\title{
CONTROL SYSTEM DESIGN OF CARDBOARD AUTOMATIC FOLDING BOX MACHINE
}

\author{
LI JING ${ }^{1}$, XU Teng-Gang ${ }^{2}$, ZHU Jian-Jun ${ }^{3}$ \\ ${ }^{1}$ College of Mechanical Engineering, Shanghai University of Engineering Science \\ ${ }^{2}$ Collegeof Mechanical Engineering, Shanghai University of Engineering Science \\ ${ }^{3}$ Engineering Training Center, Shanghai University of Engineering Science
}

\begin{abstract}
This paper introduces the design of a control system of cardboard automatic folding box machine which is based on PLC, the speed that system responses isfast, and the system has reliable operation. Through the analysis of hardware structure and working principle of the paperboard automatic folding machine box, the paper confirm the system total control scheme, and select types of the PLC, the expansion module and the touch screen, as well as distribute I/O address, according to the control requirement of the system, the paper design the program flow. Finally control system of cardboard automatic folding box machine is finished.
\end{abstract}

Keywords: PLC; automatic control; working principle; control system - ***

\section{INTRODUCTION}

Cardboard box folding machine is with the development of modern science and technology, and the development of the packaging industry to the production of goods packaging machinery. The size of the existing fixed folding box folding machine, high labor intensity, not able to solve the problem through automatic cardboard folding way. PLC as the field of industrial automatic control equipment and important ${ }^{[1]}$. Has strong function, high integration, and reliable performance advantages. This design applies the S7200PLC of SIMATIC company to the carton folding machine, so that it can complete the automatic folding operation of the carton, reduce the manual operation, reduce the labor intensity, and improve the production efficiency ${ }^{[2,3]}$.

\section{THE STRUCTURE, WORKING PRINCIPLE} AND CONTROL SCHEME OF AUTOMATIC CARTON FOLDING MACHINE

\subsection{The Hardware Structure and Function of}

\section{Automatic Carton Folding Machine}

The automatic carton folding machine is made up of 6 parts. Its structure is shown in Figure-1.

Rack Part: It's mainly divided into two parts under the frame and the upper frame. The frame adopts 50X50-5 steel welded around the seal cold plate; the upper frame is 5050 aluminum assembled, convenient adjustment, small deformation of the door frame.

Ejector Mechanism: It is mainly divided into carton manual adjustment device and fixed height feeding device.
Adjusting Mechanism: Mainly in the replacement carton, manual input parameters, institutions will automatically adjust the size of the box through the electric box size.

Material Transport Mechanism: By chuck and horizontal feeding guide rod cylinder, sucker down grab materials, horizontal feeding guide rod cylinder is conveyed to the folded position.

Folding Mechanism: The utility model mainly folds the cardboard along the fixed fold line, and all the actions of the folding mechanism are mainly completed by the cylinder.

Electrical Part: It is mainly composed of PLC, touch screen and tricolor lamp, in which PLC and touch screen are used to control part of the movement of the mechanism, and the tricolor lamp acts as a warning and warning function for normal operation. 


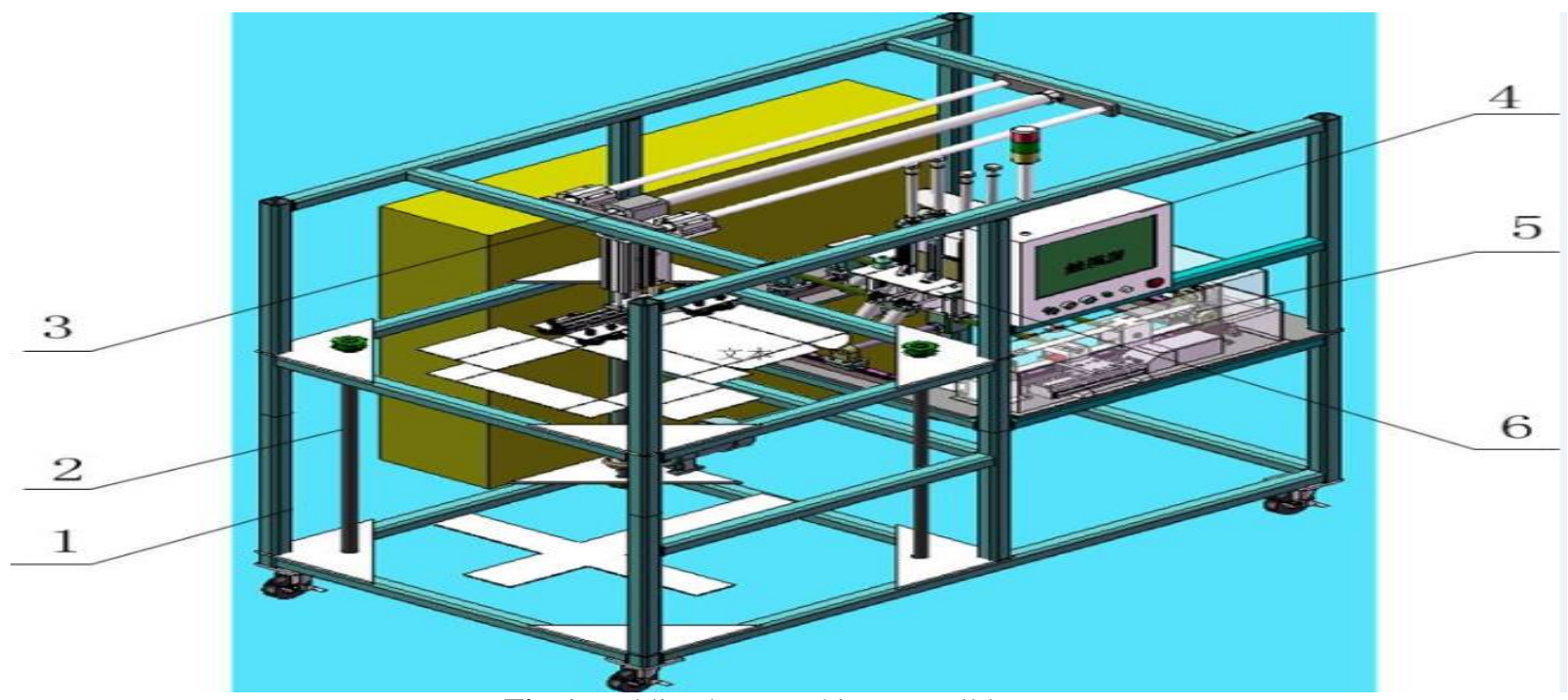

Fig-1: Folding box machine overall layout

Table-1: Name of mechanism of various parts of the cardboard automatic folding machine

\begin{tabular}{|l|l|l|l|l|l|}
\hline $\begin{array}{l}\text { Numbe } \\
\mathrm{r}\end{array}$ & Mechanism name & Number & Mechanism name & Number & Mechanism name \\
\hline 1 & Rack part: & 3 & $\begin{array}{l}\text { Material transport } \\
\text { mechanism: }\end{array}$ & 5 & $\begin{array}{l}\text { Adjusting } \\
\text { mechanism: }\end{array}$ \\
\hline 2 & $\begin{array}{l}\text { Ejector } \\
\text { mechanism: }\end{array}$ & 4 & Electrical part: & 6 & Folding mechanism: \\
\hline
\end{tabular}

\subsection{The Working Principle of Automatic Carton}

\section{Folding Machine}

According to the carton specification through the touch screen parameter setting function, realize the folding box size (length, height, width setting). Through the manual operation of the touch screen on the page corresponding to the touch button, realize the debugging of corresponding parts.
The control panel on the "manual/automatic" switch button, to start the automatic rotation state, folding box machine, paper board pushing mechanism is sent to the designated location, material transport mechanism of sucker down grab materials, horizontal feeding rodless cylinder to the folded position and the folding mechanism specified discharge the folded cardboard, will break into the fixed position along the line to complete the automatic folding carton, box process. The process flow diagram of folding carton is shown in Figure-2.

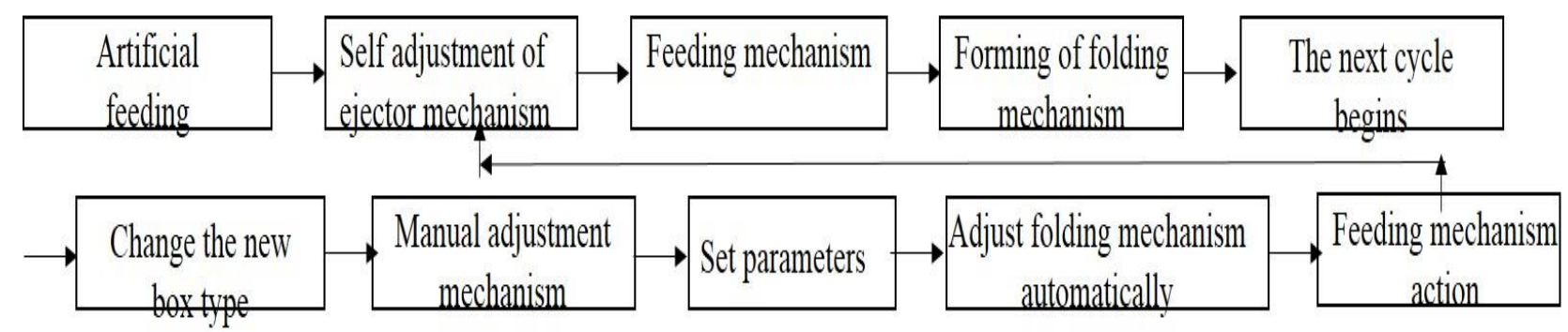

Fig-2: Flow chart of paper box folding process

\section{AUTOMATIC CARTON FOLDING MACHINE CONTROL PROGRAM}

Automatic startup, all enable signals must be met, then the control panel "manual /automatic conversion button rotates to the automatic state. According to the design capacity requirements, the folding speed folding box machine default to $800 \mathrm{PCS}$ per hour, will each time a cardboard folding carton is $3600 \mathrm{~s} / 800=4.5 \mathrm{~s} /$, the highest fold the speed is 1000PCS per hour, which is folding time is $3.6 \mathrm{~s} /$, which can be in the range of $800 \mathrm{PCS} /$ per hour-1000PCS/per hour in accordance with the actual production requirements to reasonably adjust the folding carton to the beat. The main interface of the folding machine is shown in Figure-3 


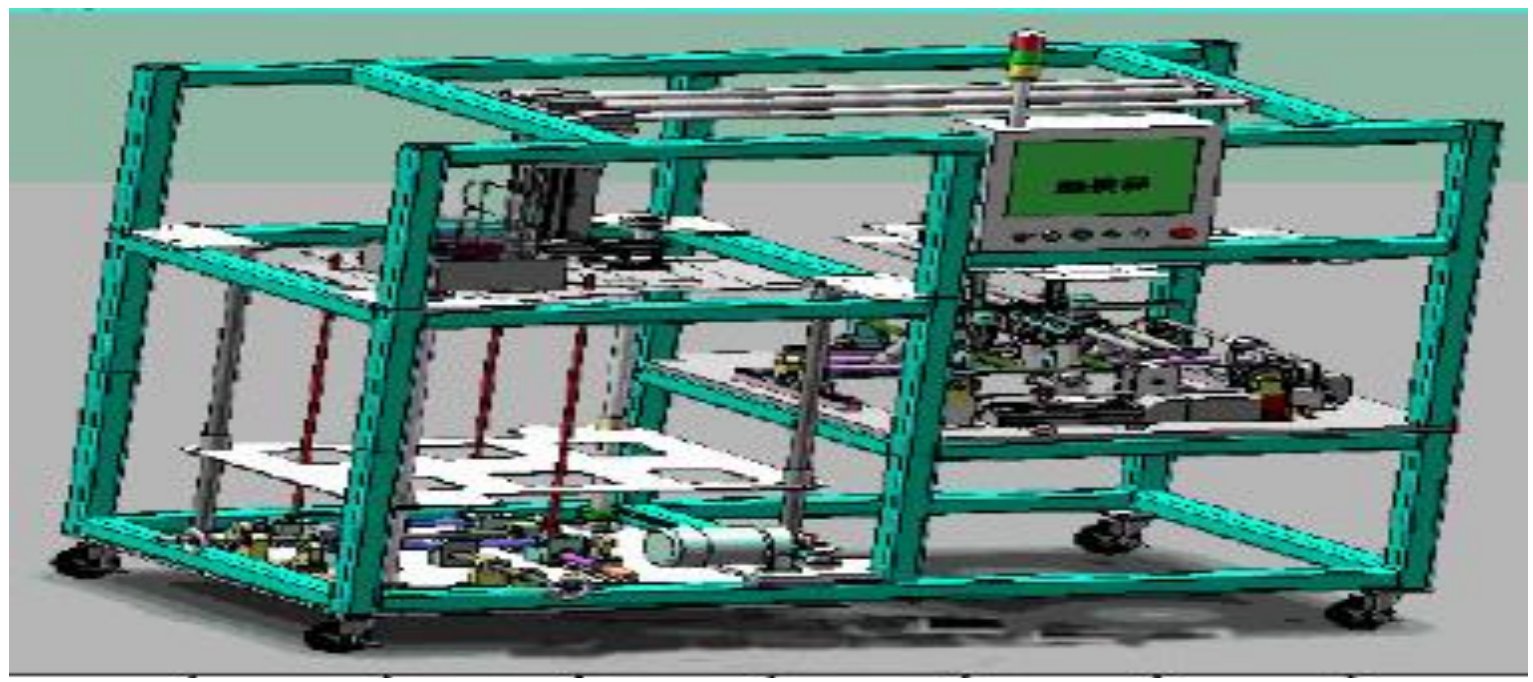

Fig-3: Main interface of folding box machine

\section{DESIGN OF CONTROL SYSTEM}

\subsection{The Composition of the Control System}

The main task of the control system is based on the folding process board to coordinate and control the mechanism of action[4], control functions mainly include: cardboard, cardboard, cardboard conveying of adjustment, cardboard folding, material shortage alarm, display parameters. Based on the above requirements, this box folding machine control system mainly consists of PLC, touch screen and all kinds of buttons, proximity switch, photoelectric sensor, pressure sensor, electric cylinder and air cylinder, controller, and switch components.

\subsection{Hardware Ddesign of Control System}

The control system of the automatic folding work process is controlled by PLC, taking into account the needs and requirements of 48DI/48DO equipment, economy and reliability, the equipment controller selects the S7-200 series PLC. of SIMATIC company S7-200 CPU226CN PLC with 24DI/16DO, the largest expansion of 128DI/128DO or 44 analog I/O program memory data memory space with $24 \mathrm{~KB}$, and $10 \mathrm{~KB}[5]$, can be used to accurately control the servo control system of AC servo motor[6].

According to the control set and PC monitoring system requirements by $\mathrm{LCD}$ touch screen to realize parameter setting and control method of the design of the system, at the start of the system, through the touch screen control system, PLC controller operation according to the analysis of the system operation requirements and operation condition, the specific operation condition judgment device; when the system is running, PLC can the receiving operator according to the requirements of the relevant control parameters set and modify the control[7].

The PLC controller and the interface technology of the touch screen is more and more stable, on the basis of the selection of SIMATIC TP270-10 color touch screen[8]. Can be loaded with specific drivers[9].

\subsection{Allocation of System Input and Output Addresses}

According to the control requirements of automatic carton folding machine, it is determined that the control system needs to configure 48 input ports and 48 output ports.

\subsection{External Wiring Diagram of PLC and Extension Module}

According to the control requirements of the automatic carton folding machine and the input and output points, the external wiring diagram is shown as shown in the Figure-4. 

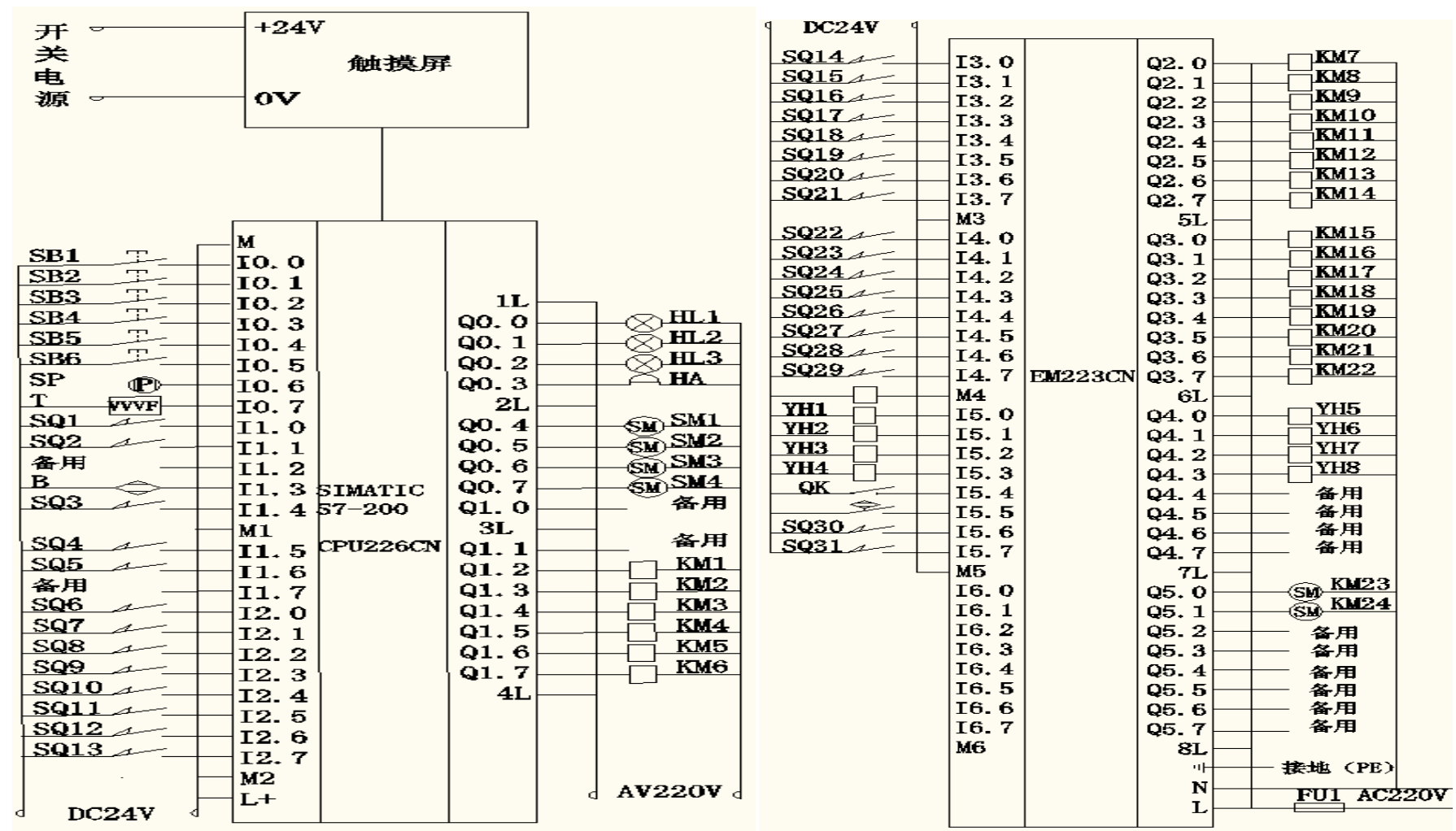

Fig-4: PLC and the expansion module exterior circuit

\section{CONTROL}

SYSTEM

SOFTWARE

\section{PROGRAMMING}

According to the control requirements of the action to be completed. The main program programming using sequential control design method for visual ladder diagram of the system. The core sequence control law is that a work cycle of the system is divided into several connected parts, which is called step, and the programming elements (such as SCR and sequence control relay a memory M) to represent each step. The output state at each step in is unchanged, and the total output of the two adjacent state step is different[10]. Therefore, according to the predetermined order, under the action of the input signal, according to the internal state, in the operation of the system, the various executing agencies automatically operate sequentially.

\section{CONCLUSION}

This system has the advantages of convenient operation, stable operation. You can manually set the touch screen box parameters, and complete parametric and automation integrated control by PLC and folding carton control system, reduce the operation of complicated process, high production efficiency, good quality automatic folding, carton production process. In the country to promote technological innovation situation next, it has good application value on the market, carton production enterprises to reduce labor costs and improve the economic efficiency of enterprises has important significance.

\section{REFERENCES}

[1]. Wang Shaohua, Tang Jin, Liu Xiaokui. Electrical control and application of PLC [M]. Changsha: Central South University press, 2008:159-160.

[2]. Hai Xin, Ma Yinzhong, Liu Shuqing. Development and typical examples of SIEMENS PLC [M]. Beijing: Posts \&amp; Telecom Press, 2010.

[3]. Chen Chen,.PLC. Characteristics and applications[J]. science and technology communication, 2012 (3): 85-86.

[4]. Zhao Hanyu, Ji Shaolong, Liu Cunxiang. The new carton packaging machine PLC control system design of [J]. light industry machinery, 2011,29 (3): 56-57.

[5]. Liao Changchu.S7-200PLC programming and application of $[\mathrm{M}]$. second edition. Beijing: Mechanical Industry Press, 2013:4-5.

[6]. Ji Shunping, Sun Chengzhi, Lu Ming, et al. SIEMENS PLC and industrial network technology [M]. Beijing: China Machine Press, 2008:20-21.

[7]. Liang Mingliang, Su Dongmin, Chang Lanzhou. Development of a grain packaging robot based on [J]., PLC, automation of manufacturing industry, 2015.37 (7): 34-35

[8]. Liang Liang. Interface design of liquid crystal touch screen based on ARM microprocessor [J]. computer measurement and control, 2011 (3): 691-693.

[9]. Song Hui, Wang Yang, Xu Qinghua. Touch screen technology and application [M]. Beijing: Chemical Industry Press, 2008:79-80.

[10]. Ji Ji, Liang Xiujuan. Implementation of complex sequential PLC control using sequential function diagrams [J]. automation of manufacturing industry, 2012.34 (7): 71 73. 